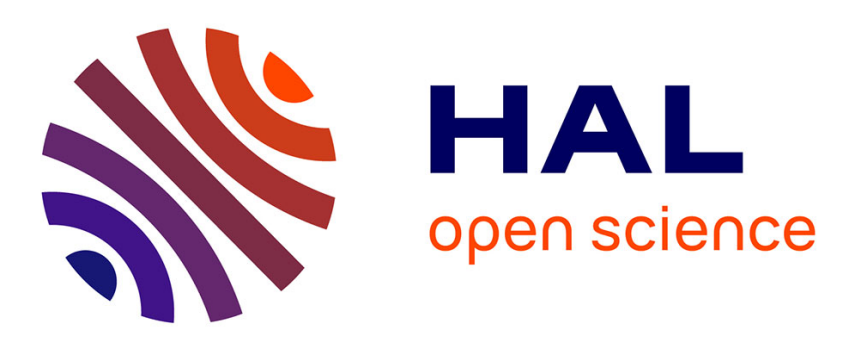

\title{
Recent developments in low temperature infrared detectors
}

\author{
Ch. Lucas, D. Amingual, J. Chatard
}

\section{To cite this version:}

Ch. Lucas, D. Amingual, J. Chatard. Recent developments in low temperature infrared detectors. Journal de Physique IV Proceedings, 1994, 04 (C6), pp.C6-177-C6-182. 10.1051/jp4:1994628 . jpa00253123

\section{HAL Id: jpa-00253123 https://hal.science/jpa-00253123}

Submitted on 1 Jan 1994

HAL is a multi-disciplinary open access archive for the deposit and dissemination of scientific research documents, whether they are published or not. The documents may come from teaching and research institutions in France or abroad, or from public or private research centers.
L'archive ouverte pluridisciplinaire HAL, est destinée au dépôt et à la diffusion de documents scientifiques de niveau recherche, publiés ou non, émanant des établissements d'enseignement et de recherche français ou étrangers, des laboratoires publics ou privés. 


\title{
Recent developments in Iow temperature infrared detectors
}

\author{
Ch. Lucas, D. Amingual and J.P. Chatard* \\ LETI - CEA , Technologies Avancées, CENG - DOPT/SLIR, 17 rue des Martyrs, 38054 Grenoble \\ cedex 9 , France \\ * SOFRADIR, 43-47 rue Camille Pelletan, 92290 Chatenay-Malabry, France
}

\begin{abstract}
: this paper indicates the state of progress of advanced infrared detection arrays in the world. This presentation is focused on high-performance cooled detectors i.e. CdHgTe photovoltaic arrays (which are more particularly emphasized), InSb detectors, PtSi Schottky barrier diode arrays, extrinsic silicon photoconductors and III-V multi-quantum well detectors. It is shown that interest may be focused on parameters other than the intrinsic detector performance alone. Future trends concerning the technologies are briefly presented. A more detailed description of the CEA-LETI-Laboratoire Infrarouge (LIR) and SOFRADIR technology is given.
\end{abstract}

\section{INTRODUCTION}

Over the last twenty years, a great deal of activity has been devoted to study and fabrication of "second generation" infrared detectors. Today, the trends are towards detector developments which are sometimes contradictory, as the demand is focused simultaneously on :

- high performances (detectivity or NEDT) which generally require cooling systems,

- achievement of television-like formats,

- integrated signal processing (smart sensors),

- if possible, reduced cooling requirements,

- low-cost manufacturing which implies compatibility with silicon integrated technology.

The progress which has been observed since the seventies on semiconductor materials used for detection and on integrated circuit technologies enables this multi-target objective to be achieved. The new detectors are characterized by their high level of integration; they are either monolithic (PtSi) or hybrid (the others).

This paper is focused on recent developments on high-performance cooled detectors and gives some prospects for each of them. The technology developed and industrialized in France (LIR and SOFRADIR) is more particularly described.

\section{TECHNOLOGICAL APPROACHES}

\subsection{Monolithic structure}

In monolithic infrared detectors, the detection sub-module is directly implemented on its readout and multiplexing circuit. Because of the required compatibility between these two elements, monolithic infrared 
detectors can be envisaged only on silicon wafers. When this compatibility is fulfilled, it obviously represents the major advantage of this structure. Today, the only detectors built-up with such a structure and being operational are PtSi/Si Schottky barrier diode arrays (see chapter 5 ).

\subsection{Hybrid structure}

Hybrid devices comprise two separate circuits (i. e. a detection circuit and a readout circuit generally manufactured on silicon) which are electrically and mechanically interconnected. Two main techniques enable these detectors to be built-up in this way:

- the indium bump technique which is widely used all over the world (Figure 1),

- the loop-hole technology mainly used by Texas Instruments (United States) and GMIRL (Great Britain).

Both these technologies present many advantages, among which :

- separate optimization and manufacturing of detection and readout circuits,

- possible assembly of circuits from various foundries provided they are prepared for this operation,

- backside illumination.

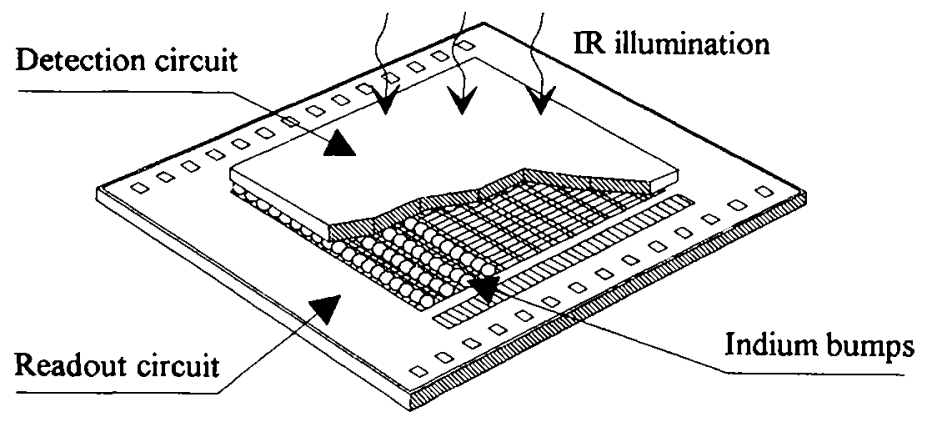

Figure 1 : schematic view of a hybrid infrared detector

In the recent past, the geometrical limitations (increase of format and reduction of pixel size) were real problems but, at present, technological improvements have been made and enable television-like formats to be achieved.

\section{CdHgTe DETECTORS}

Due to its remarkable basic properties, $\mathrm{CdHgTe}$ (cadmium and mercury telluride) is the most studied material in the field of infrared detection. The cadmium composition governs the bandgap width and therefore the cut-off wavelength of the detectors made with this material. Furthermore, $\mathrm{CdHgTe}$ presents a very high optical absorption coefficient and a low thermal generation rate, so that a $77 \mathrm{~K}$ operating temperature is commonly used for both the $3-5 \mu \mathrm{m}$ and $8-10 \mu \mathrm{m}$ spectral bands and up to $200 \mathrm{~K}$ can even be envisaged for 3-5 $\mu \mathrm{m}$ applications.

Due to the confidential nature of most of the applications (military programmes), it is difficult to know the state of the technologies precisely, but the main published achievements are given hereafter.

\subsection{3-5 $\mu \mathrm{m}$ band, $77 \mathrm{~K}$ operation}

In this range, two-dimensional arrays which are generally hybrid and backside illuminated detectors can be found. 
Table 1 : state of the art in the 3-5 $\mu \mathrm{m}$ CdHgTe range

\begin{tabular}{|l|l|c|}
\hline \multicolumn{1}{|c|}{ Countries } & \multicolumn{1}{c|}{ Companies } & \multicolumn{1}{c|}{ Detectors } \\
\hline \multirow{3}{*}{ United States } & Rockwell & $640 \times 480$ elements \\
& Hughes/SBRC & $256 \times 256$ elements \\
& Fermionics & $128 \times 128$ elements \\
& Texas Instruments & $128 \times 128$ elements \\
\hline Great Britain & GMIRL & $128 \times 128$ elements \\
\hline \multirow{2}{*}{ France } & CEA/LETI/LIR & $128 \times 128$ elements \\
& and SOFRADIR & $256 \times 256$ under way \\
\hline
\end{tabular}

It is reasonable to think that television-like products will be soon on the market with a cost compatible with military applications.

\subsection{8-12 $\mu \mathrm{m}$ band, $77 \mathrm{~K}$ operation}

In this range, because of the electrochemical sensitivity of the CdHgTe material, many more technological difficulties arise and we therefore mainly find linear arrays which are designed for scanned imaging systems. These detectors are hybrid and backside or frontside (indirect hybridization) illuminated. The existing two-dimensional arrays present formats limited to $128 \times 128$ elements.

Table 2 : state of the art of 8-12 $\mu \mathrm{m}$ CdHgTe products

\begin{tabular}{|l|l|c|}
\hline \multicolumn{1}{|c|}{ Countries } & \multicolumn{1}{|c|}{ Companies } & \multicolumn{1}{c|}{ Detectors } \\
\hline \multirow{5}{*}{ United States } & Rockwell & \\
& Hughes/SBRC & $480 \times 4$ elements \\
& Amber, Loral, etc. & \\
\cline { 2 - 3 } & Texas Instruments & $64 \times 64$ elements \\
& Fermionics & $128 \times 128$ elements \\
\hline Germany & AEG & $288 \times 4$ elements \\
\hline \multirow{2}{*}{ France } & \multirow{2}{*}{ SOFRADIR } & $288 \times 4$ elements \\
& & $480 \times 4$ elements \\
\cline { 2 - 3 } & & $64 \times 64$ elements \\
\hline
\end{tabular}

Advanced prototypes of $960 \times 4$ elements are not mentioned in this table because they are not for sale. However, they were presented in 1992 by Hughes/SBRC and LIR/SOFRADIR, which reveals the maturity of the technologies for both these manufacturers.

In fact, the international situation is very complex because of the variety of potential manufacturers particularly in the United States, but only a few of them are able to propose products for sale and in this context, the French industry (SOFRADIR) is presently in the best position.

\subsection{The LIR and SOFRADIR technology}

The basic technology which was developed at LIR in the eighties and transferred to SOFRADIR for industrialization is the so-called IRCCD technology. This is a hybrid technology as shown in Figure 1 and presented in more detail hereafter.

\subsubsection{CdHgTe material}

For infrared applications, a reduced number of defects, appropriate doping level and good uniformity of composition of the material are required. For these purposes, liquid phase epitaxy (LPE) growth of $\mathrm{CdHgTe}$ on $\mathrm{CdZnTe}$ substrates was chosen. Vapour phase techniques are still in progress because they 
seem to be the way forward for future developments. Recent results are very promising, but these techniques are not yet ready for integration in an industrial process.

\subsubsection{CdHgTe photodiode technology}

The photovoltaic detectors are achieved by a planar process on p-type material, the $\mathrm{n}$ region being formed by ion implantation (this method requires only low heating treatments). The technological process for junction formation, interfaces, insulators and achievement of electrical contacts is very well mastered and leads to high yield for production of high-performance detectors.

A new n-on-p planar process for photodiode fabrication is being studied at LIR. It gives dark current values which are close to the theoretical limits and comparable to data published in the United States for $p$ on- $n$ heterojunctions. This remarkable result remains to be mastered before the process is transferred to SOFRADIR for industrialization.

\subsubsection{Hybridization}

At the beginning of the eighties, the choice was made in France to use the indium bump technique which enables high-performance $\mathrm{CdHgTe}$ photodiode arrays to be combined with various silicon readout circuits (CCD or CMOS or possibly others). This technique has been thoroughly studied and high-precision automated machines developed leading to excellent fabrication yields close to $100 \%$.

\subsubsection{Readout and multiplexing circuits}

As previously mentioned, the readout and multiplexing silicon circuits can be provided by various foundries, but the French manufacturer for specific applications i.e. Thomson-TCS, the production lines of which being qualified for low temperature operating conditions, is generally used.

\subsection{SOFRADIR products}

\subsubsection{3-5 4 m applications}

Today, the basic products are the $128 \times 128$ element IRCCD arrays. The development of $256 \times 256$ element arrays is under way at LIR and SOFRADIR and should be ready for production in 1995.

\subsubsection{8-12 4 m applications}

The main available products are $288 \times 4$ linear arrays operating in a Time \& Delay Integration (TDI) mode (typical detectivity $\left.=2.10^{11} \mathrm{~cm} \cdot H z^{1 / 2} \cdot \mathrm{W}^{-1}\right)$. These detectors have been sold in many countries for evaluation and successfully tested in military environmental conditions. As a matter of fact, they are now in production for larger quantities in order to be integrated in American systems. This shows the maturity of this technology which is available in France and not yet in the United States. The more recently developed $480 \times 4$ products (see Figure 2) are now also available with typical performances similar to those of the $288 \times 4$.

Figure 2 : SOFRADIR $480 \times 4$ element linear array (8-12 $\mu \mathrm{m})$

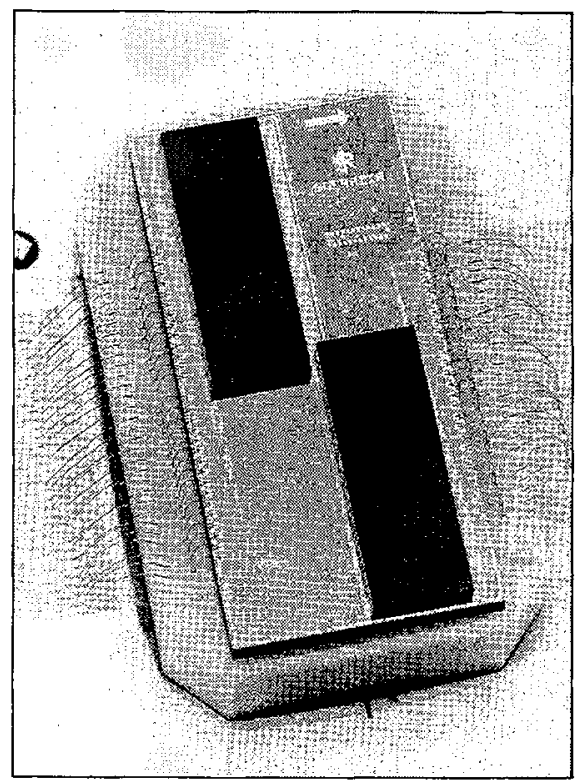




\section{InSb DETECTORS}

The InSb material is particularly well suited for infrared detection in the $3-5 \mu \mathrm{m}$ spectral range as its bandgap width is $225 \mathrm{meV}$ at $80 \mathrm{~K}$, which corresponds to a $5.5 \mu \mathrm{m}$ cut-off wavelength.

This material is very well mastered on large surfaces (typically $2 "$ ) and the photodiode technology processed on it is mature enough to lead to manufacture of large format arrays in the United States.

Table 3 : state of the art of InSb infrared detectors

\begin{tabular}{|c|l|c|}
\hline Countries & \multicolumn{1}{c|}{ Companies } & Detectors \\
\hline United States & $\begin{array}{l}\text { Amber } \\
\text { Hughes/SBRC }\end{array}$ & $512 \times 512$ elements \\
\hline
\end{tabular}

If we compare InSb to $\mathrm{CdHgTe}$, it appears as a very strong competitor for $3-5 \mu \mathrm{m}$ applications at $77 \mathrm{~K}$, but the fact that it does not cover the 8-12 $\mu \mathrm{m}$ spectral range proves to be a major drawback for industrialization (necessity of several production lines to cover all the fields of application). On the other hand, this type of detector cannot accept to work at a higher temperature.

\section{PtSi SCHOTTKY BARRIER DIODE ARRAYS}

PtSi Schottky barrier detectors operate at $77 \mathrm{~K}$. The major advantage of this technology is the full compatibility with silicon VLSI technology enabling large format arrays to be manufactured (television-like formats are already obtained) with low defect counts, high yields and relatively low fabrication costs.

The following table shows the diversity of potential manufacturers, especially in the United States.

Table 4 : state of the art in the PtSi Schottky detector field

\begin{tabular}{|l|l|c|}
\hline \multicolumn{1}{|c|}{ Countries } & \multicolumn{1}{c|}{ Companies } & Detectors \\
\hline \multirow{3}{*}{ United States } & $\begin{array}{l}\text { David Sarnoff Lab } \\
\text { Ford Aerospace } \\
\text { Fairchild, Kodak } \\
\text { Hughes, etc. }\end{array}$ & $\begin{array}{c}512 \times 512 \text { elements } \\
\text { or }\end{array}$ \\
\hline Japan & Mitsubishi & $1040 \times 1040$ elements \\
\hline
\end{tabular}

Up to recently, these detectors were considered as being very promising, but their admitted drawbacks (low quantum efficiency, limited spectral response, cooling necessity, low frame rate) prove to be drastically limiting for advanced systems, which has now reduced interest in them.

\section{EXTRINSIC SILICON PHOTOCONDUCTORS}

Extrinsic silicon detectors operate at very low temperature. They cover a large spectral range depending on the doping impurity utilized. These detectors are suited to operation in low background environments where very high performances are required (scientific or specific applications).

The devices presented in table 5 have all been achieved for astrophysics. Most of them are gallium doped silicon photoconductors (cut-off wavelength $=17 \mu \mathrm{m}$ ), operating at very low temperature (down to $4 \mathrm{~K}$ ) and read by Direct Voltage Readout (DVR) silicon circuits.

The BIB technology is a variant of the extrinsic technology mainly developed in the United States, using the properties of very highly doped silicon (As doped Si). In Europe, this technology has been approached but remains less well mastered. 
Table 5 : state of the art of extrinsic silicon detectors

\begin{tabular}{|c|c|c|}
\hline Countries & Companies & Detectors \\
\hline United States & $\begin{array}{l}\text { Hughes/SBRC } \\
\text { Rockwell } \\
\text { Amber }\end{array}$ & $\begin{array}{l}\text { S } 58 \times 62 \text { elements } \\
128 \times 128 \text { elements }\end{array}$ \\
\hline & Rockwell & $256 \times 256(\mathrm{BIB})$ \\
\hline France & CEA/LETI/LIR & $\begin{array}{c}32 \times 32 \text { (ISO) } \\
64 \times 64 \text { (OBSOL) }\end{array}$ \\
\hline
\end{tabular}

Manufacturing of $128 \times 192$ element gallium doped silicon photodetectors is currently under way at CEA/LETI/LIR. This development will be brought out within the next few months.

\section{III-V MULTI-QUANTUM WELL DETECTORS}

The concept of infrared detection by inter-sub-band absorption in III-V superlattices was reported at the beginning of the eighties and extensive research work is being carried out on this type of detectors.

The main advantage in multi-quantum well detector development is ease of fabrication, as vapour phase deposition techniques of $\mathrm{GaAl} / \mathrm{GaAlAs}$ structures are quite mature and sensor development can benefit from a proven GaAs integrated technology. The potential ability of these detectors to control the detection wavelength electrically is very attractive but remains to be proven.

Among the admitted drawbacks, the low operation temperature required $(<60 \mathrm{~K})$ drastically limits the scope of medium-term applications in the $8-12 \mu \mathrm{m}$ spectral range. We may foresee that these detectors will be used only for specific applications (niches).

Table 6 : state of the art in the field of III-V multi-quantum well detectors

\begin{tabular}{|l|l|c|}
\hline \multicolumn{1}{|c|}{ Countries } & \multicolumn{1}{c|}{ Companies } & \multicolumn{1}{c|}{ Detectors } \\
\hline United States & Bell Laboratories & $256 \times 256$ elements \\
\hline Sweden & IMC & $128 \times 128$ elements \\
\hline France & Thomson/LCR & $128 \times 128$ elements \\
\hline
\end{tabular}

\section{CONCLUSION}

Different families of infrared detectors have been dealt with. In conclusion, if we try to compare them, at least three parameters which seem to be essential are to be considered : electro-optical performances, operating temperatures and maturity of the technologies. With such criteria, $\mathrm{CdHgTe}$ detectors which are high-performance, well mastered up to production, and cover both the 3-5 and 8-12 $\mu \mathrm{m}$ spectral ranges (with $\mathrm{T} \geq 77 \mathrm{~K}$ ), will probably remain in a leading position for all "second generation" applications.

\section{ACKNOWLEDGEMENTS}

Most of the LIR and SOFRADIR activities presented in this paper are sponsored by the French Ministry of Defence (DGA-DRET, DGA-DME and DGA-DEI). The French Space Agency (CNES) partly sponsors the programmes dedicated to space applications and astrophysics. 